\title{
Characteristics of Winter Clouds and Precipitation over the Mountains of Northern Beijing
}

\author{
Xincheng Ma, ${ }^{1,2,3}$ Kai Bi, ${ }^{1}$ Yunbo Chen, ${ }^{1}$ Yichen Chen, ${ }^{1,2}$ and Zhigang Cheng ${ }^{3}$ \\ ${ }^{1}$ Beijing Weather Modification Office, Beijing 100089, China \\ ${ }^{2}$ Beijing Key Laboratory of Cloud, Precipitation and Atmospheric Water Resources (LCPW), Beijing Meteorological Bureau, \\ Beijing 100089, China \\ ${ }^{3}$ Institute of Urban Meteorology, CMA, Beijing 100089, China
}

Correspondence should be addressed to Kai Bi; becare2008@163.com

Received 27 July 2017; Revised 31 October 2017; Accepted 22 November 2017; Published 14 December 2017

Academic Editor: Lulin Xue

Copyright (C) 2017 Xincheng Ma et al. This is an open access article distributed under the Creative Commons Attribution License, which permits unrestricted use, distribution, and reproduction in any medium, provided the original work is properly cited.

There are few studies which reported the characteristics of winter clouds and precipitation in the Haituo Mountains of Northern Beijing where the 2022 Winter Olympic Games will be held. This paper outlines comprehensive datasets, including the surface measurements, remote sensing and aircraft measurements, to study cloud and precipitation characteristics over the mountainous terrain. The analysis results show (1) high-level trough and vortex were the main weather system in all 12 cases. (2) $58 \%$ of precipitation occurred only at night, and only $8 \%$ of snowfall occurred only at daytime, but under the surface inverse trough snowfall (in 4 of the 12 cases) persisted from night to day peaking at 20 hours; Snowfall persisted at least 3 hours in $83 \%$ of the snowfall, $5-10$ hours in $50 \%$ of cases, and more than 10 hours in $33 \%$ of the storms. In $67 \%$ of cases, the maximum snowfall occurred within the initial 1-2 hours. (3) In 12 cases, 83\% of orographic clouds reached Yan Jiaping, after increased southwesterly winds, resulting in visibility below $100 \mathrm{~m}$. (4) during snowfall, The dominant wind direction is southwest. The start of the snowfall corresponded with an increase in southwesterly wind. The snowfall is maintained according to with the strengthening of southwesterly wind and dissipated accordingly with the receding of southwesterly wind. Whenever the snowfall stopped, the northwest wind was strong at all heights. (5) The first peak value of integral liquid water appeared in the early stage of snow, and we also observed integral liquid water increases with orographic cloud uplift, presenting potentially favorable seeding opportunities in 10 cases. (6) The primary crystal habits collected at Yan Jiaping during steady snowfall were rimed and aggregated planar dendrites.

\section{Introduction}

The 2022 Winter Olympic Games will be held in the Haituo Mountains of northern Beijing. To ensure a successful Winter Olympics, natural snow cover is a required meteorological condition. Climatological statistics show North China's snowfall to be decreasing [1]. Weather modification in the Haituo Mountains region has been considered for winter snowpack augmentation. The success of weather modification in this region requires a clear knowledge of the natural clouds and precipitation which can enhance local snowfall.

The success of harnessing scientific weather modification technology to augment precipitation in mountainous regions is critically dependent on understanding precipitation processes. Since the 1940s, surface, remote sensing, and aircraft measurements have been used over the mountain ranges of the western United States to study cloud and precipitation characteristics [2-5]. During the 1980s, China commenced airborne and ground observations to study winter precipitation processes over Tian Mountains in the Xinjiang Uygur Autonomous Region of the western China [6-9]. These studies show significant differences between mountain regions, which highlight the need to study and understand the varied regional winter characteristics of cloud systems in mountain regions. Recent innovations have seen observational advances in airborne cloud radar and lidar and ground-based mobile radars using in situ measurements [10]. Such measurement technology can improve our understanding of the key features of natural precipitation in mountains. 


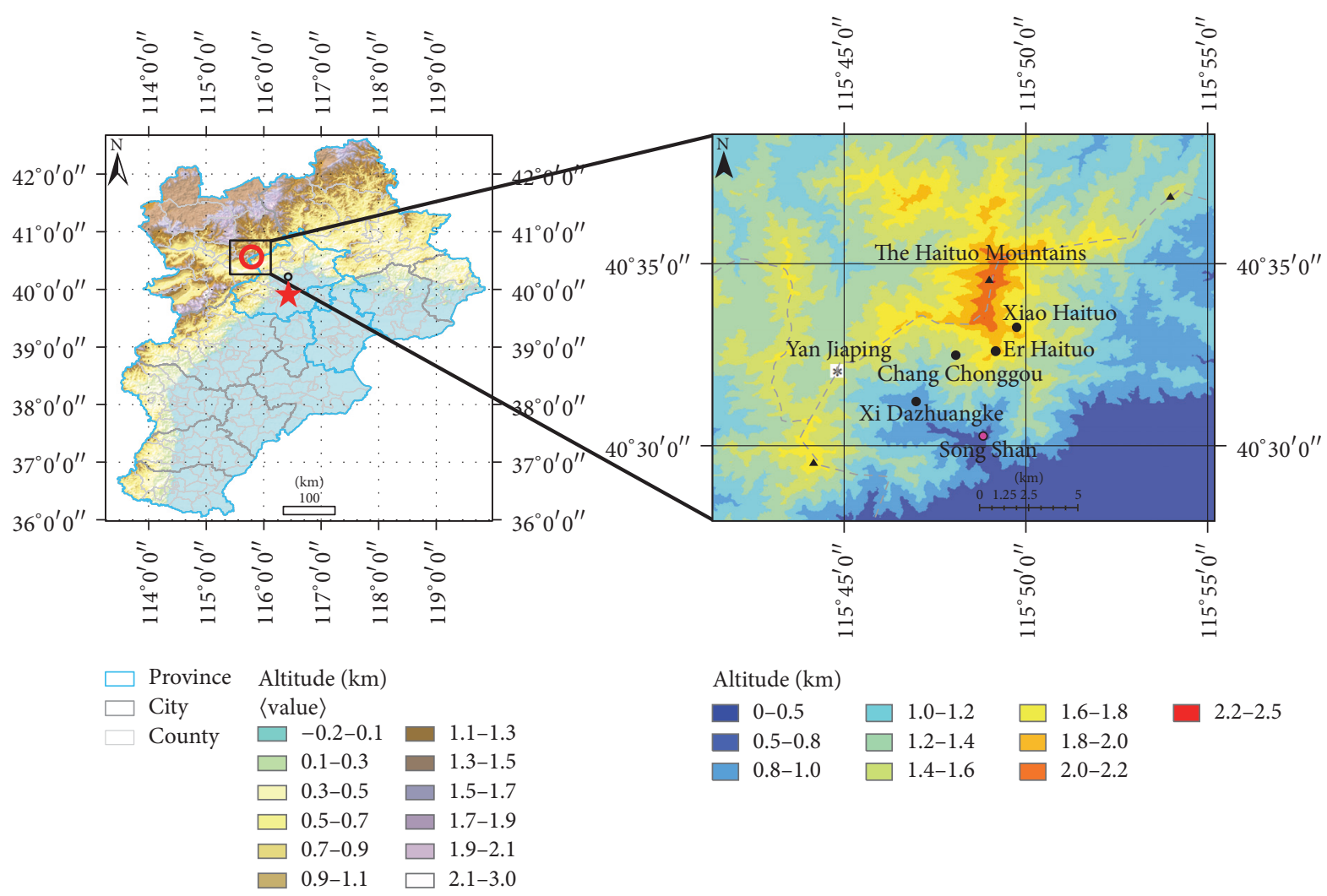

(a)

(b)

FIGURE 1: (a) Location of the Haituo Mountains (red circle) experimental area (black box) and airport (black circle) in the Beijing and Hebei province; red star is downtown Beijing. (b) Location and orography $(\mathrm{m})$ of the Yan Jiaping integrated observation station (snowflake) and meteorological automatic stations (black and red points) and black triangle is the top of the Haituo Mountains.

Previous observations of winter cloud and precipitation are rare in the Haituo Mountains [11]. Between 2016 and 2022 topographic precipitation and integrated cloud-seeding experiments (TOP-ICE) will be conducted by the Beijing Weather Modification Office (BWMO) in the Haituo Mountains of Northern Beijing to determine (1) the natural conditions of winter clouds and precipitation, (2) the evaluation of precipitation enhancement potential in this region, (3) the effects of integrated seeding (by aircraft and on-ground) on the clouds and precipitation in the Haituo Mountains. This study is primarily focused on the first objective and part of the second objective.

The BWMO's first observation program in the Haituo Mountains began during the winter of 2016/17. The purpose of these experiments is to describe the natural structure of the winter clouds systems and assess the potential for snowfall augmentation. The paper is based on data collected during the 12 cases of snowfall. Natural cloud and precipitation characteristics are studied using surface, remote sensing, and aircraft measurements. Ludlam [12] presented a conceptual model of seeding mountain clouds to enhance snowfall by tapping the supercooled liquid water (SLW). Research indicates that winter orographic clouds are suitable for seeding to increase snowfall [13]. In order to evaluate precipitation augmentation potential, aircraft and ground-based instruments such as radiometers
[14-16] measure sustained supercooled liquid water (SLW) in orographic clouds. In this paper, radiometer and airborne measurements are used to examine the characteristics of the supercooled water fields. The following section compares two case studies that illustrate the physical structure and temporal evolution of snowfall systems during the early stage, stable period, and end of snowfall. One case analyzes the microphysics of snow clouds. The habits of solid precipitation particles on the ground are studied in the context of snowfall.

\section{Data and Methods}

2.1. Research Site. The Haituo Mountains (Figure 1), which form part of the Yan Mountains located approximately $90 \mathrm{~km}$ northwest of downtown Beijing, run from the northwest to southeast. The mountain tops $(2241 \mathrm{~m}$, all height is above mean sea level) are flat, $10 \mathrm{~km}$ long, and $500 \mathrm{~m}$ wide. Meteorological automatic stations were built in 2014. Field measurements in the winter of 2014-2015 show the average snowfall per storm during the winter season is $0.37 \mathrm{~mm}$ near the top of the mountains at Xiao Haituo $(2018 \mathrm{~m})$ and is about $0.63 \mathrm{~mm}$ on the mountainside at Chang Chonggou $(1316 \mathrm{~m})$. It is about $0.80 \mathrm{~mm}$ near the bottom of the mountain at $\mathrm{Xi}$ Dazhuangke (928 m). 
The airport lies $64 \mathrm{~km}$ southeast of the Haituo Mountains, and flights are restricted to the region above the Minimum Enroute Altitude, $2900 \mathrm{~m}$. The Yan Jiaping (YJP), located at " $115^{\circ} 44^{\prime} \mathrm{N}, 40^{\circ} 31^{\prime} \mathrm{E}$, and $1344 \mathrm{~m}$," houses the integrated observation system, which is about $6 \mathrm{~km}$ southwest of the ridge of the Haituo Mountains.

2.2. Surface Measurements. The following instrumentation was available during the winter of 2016/17: a meteorological automatic station with 6 elements (temperature, humidity, pressure, wind speed, wind direction, and precipitation gauges) at Xiao Haituo, Er Haituo (1805 m), Chang Chonggou, and Xi Dazhuangke and a meteorological automatic station with 5 elements (temperature, humidity, pressure, wind speed, and wind direction) at Song Shan (756 m). The automatic precipitation gauge type is HYA-APG from China Huayun Corporation. With a sensitivity of $0.1 \mathrm{~mm}$, the maximum measurement error is $\pm 0.4 \mathrm{~mm}$. The Beijing Meteorological Service (BMS) information center calibrates precipitation data (including meteorological automatic station data). The sounding site is at Guan Xiangtai (54511) near downtown Beijing, located $90 \mathrm{~km}$ southeast of the Haituo Mountains. Soundings during snowfall can provide background information on the synoptic environmental condition for the Haituo Mountains area.

The YJP has a FM-100 droplet spectrometer (from USA DMT Inc.), a precipitation disdrometer, a visibility sensor, a Bigg type mixing cloud chamber $(5 \mathrm{~L})$, and portable sixelement (temperature, humidity, pressure, wind speed, wind direction, and solar total radiation) automatic weather station. In the absence of automatic precipitation gauges, the Chinese standard precipitation gauge is used to measure precipitation, while the snow depth data is collected by the vernier caliper near the precipitation gauge. Experiments found the Chinese standard precipitation gauge to catch $73 \%$ of the relative ground true snowfall [17]. Joint size and fall velocity distributions of particles were measured with a Particle Size and Velocity (PARSIVEL) precipitation disdrometer [18]. Meanwhile, the habits rime and aggregation characteristics of YJP's snowfall are captured by photomicrography on $7.6 \mathrm{~cm} \times 2.6 \mathrm{~cm}$ slides. Measurements of about 5 to 30 seconds are collected throughout the storm.

2.3. Instruments on the Aircraft. Aircraft measurements listed in this paper were made during case 1. The data was provided by a Kingair350 cloud research aircraft provided by the BWMO. The primary instruments used in this report included a Fast Cloud Droplet Probe (FCDP), 3V-CPI, and Aircraft Integrated Meteorological Measurement System (Aimms-20).

FCDP, developed by SPEC Inc., measures particles by detecting the amount of light scattered into the optics aperture during particle interaction through a laser beam. FCDP includes FSSP-300 optics with pinhole limiting depth of field [19]. FCDP has 20 equally spaced bins and can size particles from $2-50 \mu \mathrm{m}$ with a resolution of $3 \mu \mathrm{m}$. The LWC in this report was calculated by the FCDP result.

The 3V-CPI probe, made by SPEC Inc., combines the cloud particle imager (CPI) and the 2D stereo probe (2D-S) into a single instrument. $2 \mathrm{D}-\mathrm{S}$ is an airborne instrument that measures the size, shape and concentration of particles by two cross-sectional laser arrays [20]. 2D-S V channel operates in the $10-1280 \mu \mathrm{m}$ (10 $\mu \mathrm{m}$ resolution). 2D-S H channel operates in the $50-6400 \mu \mathrm{m}(50 \mu \mathrm{m}$ resolution). The cloud particle imager (CPI) is triggered by the $2 \mathrm{D}-\mathrm{S}$ to cast images of particles on a $1024 \times 1024$ pixels' charged coupled device (CCD). CPI captures images of particles from $10 \mu \mathrm{m}$ to $2 \mathrm{~mm}$ [21].

Probes are calibrated annually before the measurement season and instruments are maintained before and after each flight.

The research aircraft, Kingair-350, obtained the aircraft data for case 1 during winter.

2.4. Remote Sensing and Other Measurements. Date from the wind profile radar (Airda-3000, from Chinese Airda Company), a 35-channel microwave radiometer, and an $8 \mathrm{~mm}$ wave-length cloud radar were collected at YJP. The wind profile radar supplied information on wind speed and direction at standard altitudes. The detection frequency of the wind profile radar is $1290 \mathrm{MHz}$, and the detection accuracy of wind speed and direction is $\leq 1.5 \mathrm{~m} / \mathrm{s}$ and $\leq 10^{\circ}$. The radiometer monitored the temporal and spatial evolution of the cloud liquid water field. The cloud radar monitored cloud echo characteristics and echo top height, and it was introduced by Zhong et al. [22]. The complementary symmetrical pulse technology is used in $8 \mathrm{~mm}$ wave-length cloud radar for weak echo intensity cloud.

The wide pulse performs well in weak echo intensity detection, but it misses information of lower altitude cloud. The narrow pulse is used for supplement of lower level cloud, but it has limited detecting ability. The gap in Figure 6 shows the situation with weak echo intensity at lower height. Synoptic data and satellite data were sourced from the China Meteorological Administration (CMA) and the University of Wyoming (UW). BMS provided meteorological automatic station data analyses. The Magono and Lee [23] crystal classification is also used.

2.5. Case Information. Twelve snowfall cases were collected during the winter of 2016/17 (Table 1). Synoptic condition was analyzed according to the weather map at 0800 or 2000 (all times are local) during the snowfall, and snowfall characteristics were collected at YJP. Frequent unsafe flying conditions limited the aircraft measurements to 1 of the 12 cases, and the weather conditions were similar for case 1 and case 9 and case 11 . The case 1 aircraft results were therefore used as a supplement to the cloud information in those cases.

The 12 snowfall cases occurred in three kinds of synoptic environments. Climatic statistics indicate the main snowfall synoptic systems to be low trough, low vortex, and return flow [24]. The next section illustrates the precipitation processes within three typical cases. The cases include two examples of a trough storm (21 February 2017 and 16 January 2016) and a low vortex snowfall (7 January 2017). In the following section, two case studies are compared that illustrate the physical structure and temporal evolution of snowfall systems during the early stage, stable period, and end. One case analyzes the 


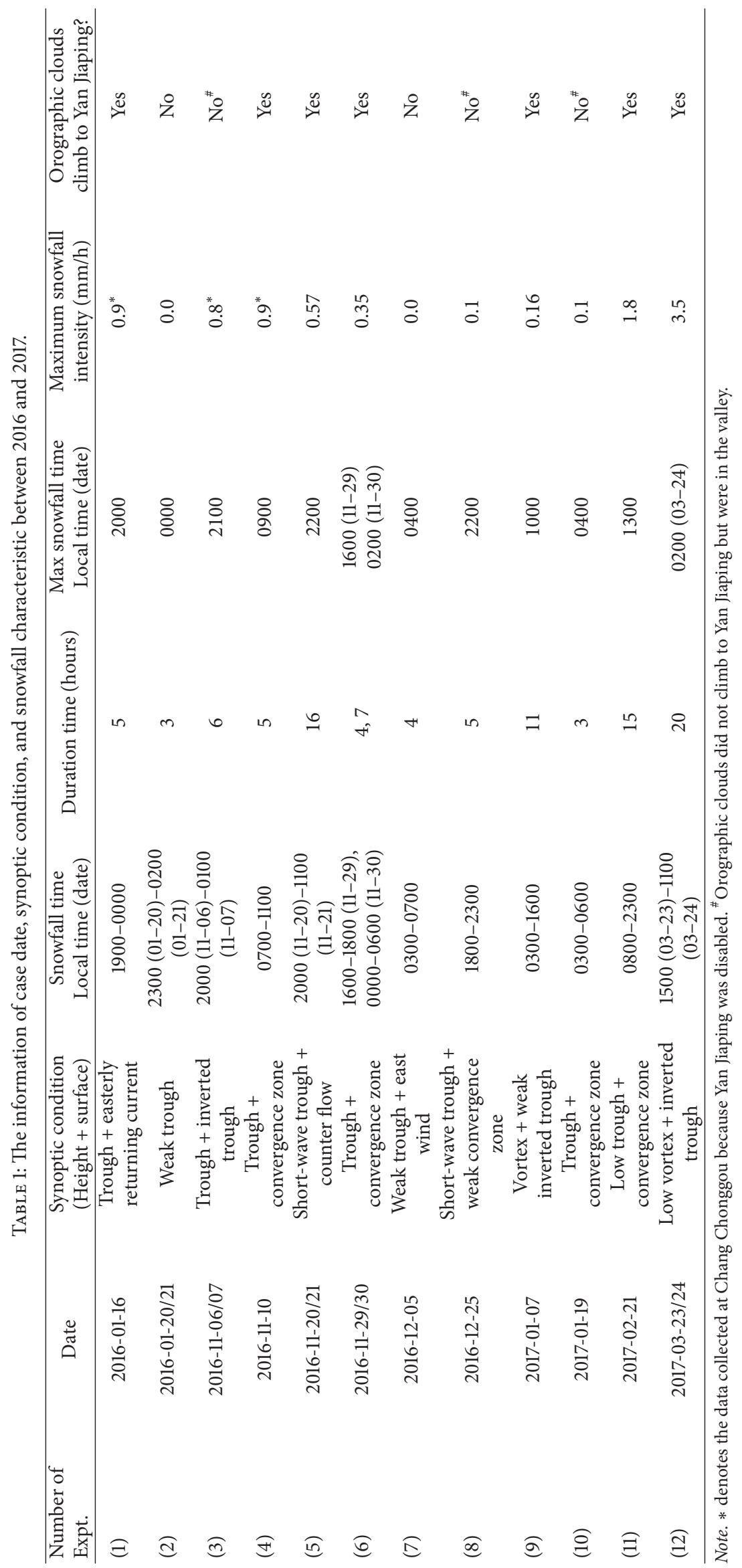



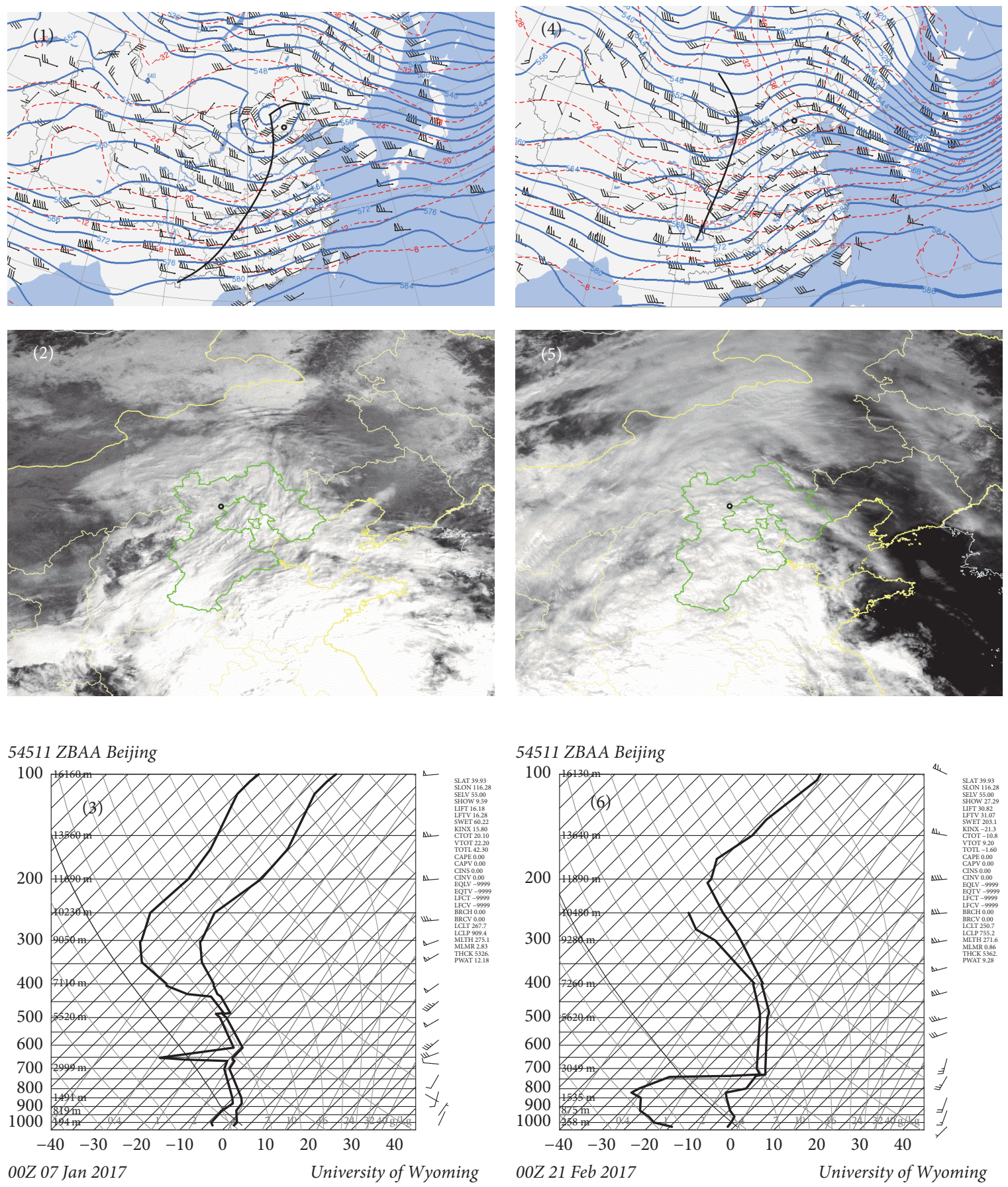

FIGURE 2: The $500 \mathrm{hPa}$ analysis of height, temperature field, wind, and sounding in Guan Xiangtai (54511) at 0800 on 7 January 2017 (1, 3) and 21 February $2017(4,6)$ and visible satellite image of the 7 January 2017 (2) at 1000 and the 21 February 2017 (5) at 1300. Black circle is the Haituo Mountains region.

microphysics of snow clouds. The habits of solid precipitation particles on the ground are studied in the context of snowfall.

\section{Results and Discussion}

3.1. Some General Characteristics of Snowfall. Table 1 shows the main synoptic systems at high altitude to be the low trough and the low vortex with the convergence zone, inverted trough, or easterly returning current on the ground. Moderate or heavy snowfall often occurs with a low trough or vortex and the inverted trough or easterly returning current occurring concurrently. The weak trough produces little snow in the mountainous areas with no snow cover in the ground. Figure 2 shows the $500 \mathrm{hPa}$ analysis of height, temperature field, and sounding in Guan Xiangtai (54511) and the satellite image on 7 January 2017 (case 9) and 21 February 


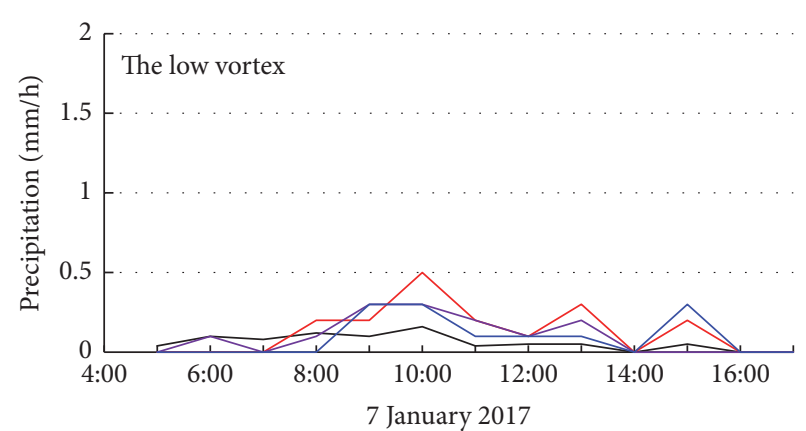

— Yan Jiaping-1344 m
Xi Dazhuangke-928 m
Er Haituo-1805 m

(a)

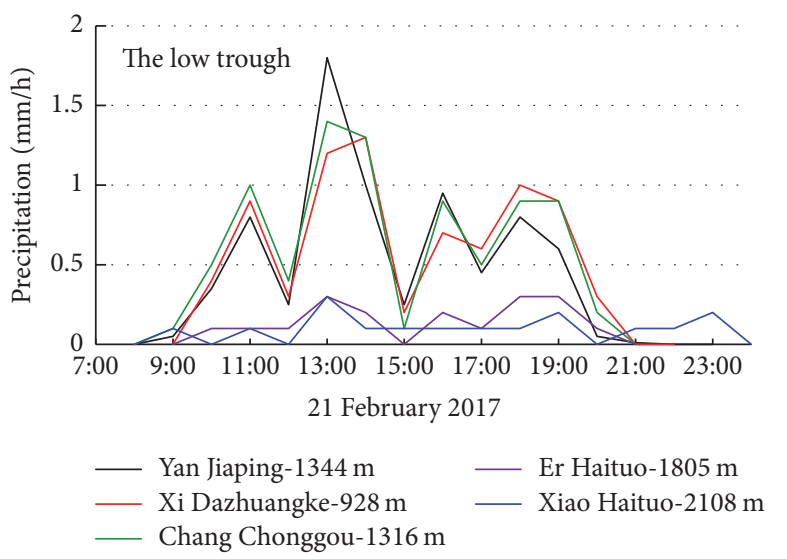

(b)

FIGURE 3: Distribution of precipitation rates at different altitudes under typical low vortex (case 9, (a)) and low trough (case 11, (b)) in the Haituo Mountain.

2017 (case 11). The satellite image captures the moment of maximum snowfall in case 9 and case 11. The cloud system in case 11 is deeper and more widely distributed than in case 9, and the cloud system in both cases moved from the southwest to the northeast over the Haituo Mountains. During the snowfall, the water vapor around Beijing is supported by southwesterly airflows in the low level. The average elevation of the Haituo Mountain is above $1500 \mathrm{~m}$ (about $850 \mathrm{hPa}$ ). The sounding of Guan Xiangtai (54511) shows the water saturation is distributed from $850 \mathrm{hPa}$ to $450 \mathrm{hPa}$ in case 11, while the air is saturated only from $850 \mathrm{hPa}$ to $550 \mathrm{hPa}$ in case 9. In case 11 the southwesterly wind was stronger than in case 9, corresponding to the water saturation region. As a result the maximum snowfall of case 11 is ten times greater than case 9 especially in front of the mountain (Figure 3). The distribution of precipitation rates at different altitudes under typically low vertex (case 9) and low trough conditions (case 11) in the Haituo Mountain indicates that the two typical synoptic conditions affect the precipitation rates.

Table 1 lists the snowfall time, duration, maximum snowfall time, maximum snowfall intensity, and whether orographic clouds climb to YJP in various cases. 92\% (12 cases) of the precipitation times were continuous (except case 6). The sunrise is about 0700 in winter Beijing. The sunset time is about 1700 . Therefore, night refers to $1700-0700$, and daytime is $0700-0700$. Of the 12 cases, $58 \%$ of precipitation occurred only at night (1700-0700) and only $8 \%$ of snowfall occurred only at daytime (0700-1700). Furthermore, $34 \%$ of the snowfall lasts from night to daytime. Under the surface inverse trough, snowfall ( 4 of the 12 cases) lasted longer from night to daytime with the maximum being 20 hours. Snowfall sustains more than 3 hours in $83 \%$ of the cases. $50 \%$ of the precipitation cases last $5-10$ hours and $33 \%$ of the storms snow more than 10 hours. The maximum snowfall presented at the earlier stage (within 1-2 hours after the snowfall began) in $67 \%$ of the cases. The maximum snowfall intensity was $3.5 \mathrm{~mm} / \mathrm{h}$ with an average $0.8 \mathrm{~mm} / \mathrm{h}$.

Manned observation at YJP showed $83 \%$ of orographic clouds in 12 cases, which resulted in visibility below $100 \mathrm{~m}$ and climbed to YJP along the southeast and southwest of the valley during precipitation and returned to the valley or disappeared after the snowfall stopped. Some cases (23 March 2017, 10 November 2016, and 21 February 2017) showed repeated movement of orographic clouds to the station, hovering in the valley at times.

The surface temperature is critical for cloud seeding with ground-based AgI generators in the Haituo Mountains. The elevation of Xi Dazhuangke is about $928 \mathrm{~m}$. The ground generators for seeding occur at an elevation of 900-1000 m. Surface temperature is a major indicator whether ground-based seeding is effective. It lacks temperature sensor near generators. Statistics of ground temperature at Xi Dazhuangke during snowfall show the average ground temperature to be below $0^{\circ} \mathrm{C}$ and the average surface temperature in November, December, January, February, and March to be $-2.4^{\circ} \mathrm{C}$, $-4.9^{\circ} \mathrm{C},-7.1^{\circ} \mathrm{C},-6.8^{\circ} \mathrm{C}$, and $-1.3^{\circ} \mathrm{C}$, respectively. The 2022 Winter Olympic Games will be held in February, so the temperatures may then be suitable for ground cloud seeding. The 2022 winter Paralympic games will be held in March, and surface temperature will not be in better conditions.

\subsection{Characteristics of Snowfall Evolution}

3.2.1. Early Stage of Snowfall. Before snowfall, the clouds are generally layered at high levels over the Haituo Mountains. The reflectivity of clouds is about $-5 \mathrm{dBZ}( \pm 5 \mathrm{dBZ})$ in case 9 (0300-0500). In case 11 (0700-0900), the reflectivity of clouds vary from 0 to $5 \mathrm{dBZ}$ and the maximum echo intensity is near $8 \mathrm{~km}$ with corresponding temperature of $-45^{\circ} \mathrm{C}$. At ground level the orographic cloud climbs the mountains but does not move to YJP. With the southwesterly wind at low level and orographic climbing to YJP (Figure 4), snowfall starts at YJP.

Microwave radiometer observation shows that, during the snow formation stage, the integral liquid water (ILW) gradually increases and reaches the first peak value of about $0.15 \mathrm{~mm}$ in case 9 and case 11, with the distribution of liquid water content (LWC) from $1344 \mathrm{~m}$ up to about $4.5 \mathrm{~km}$ (Figure 5), which indicates more SLW at the start of the 


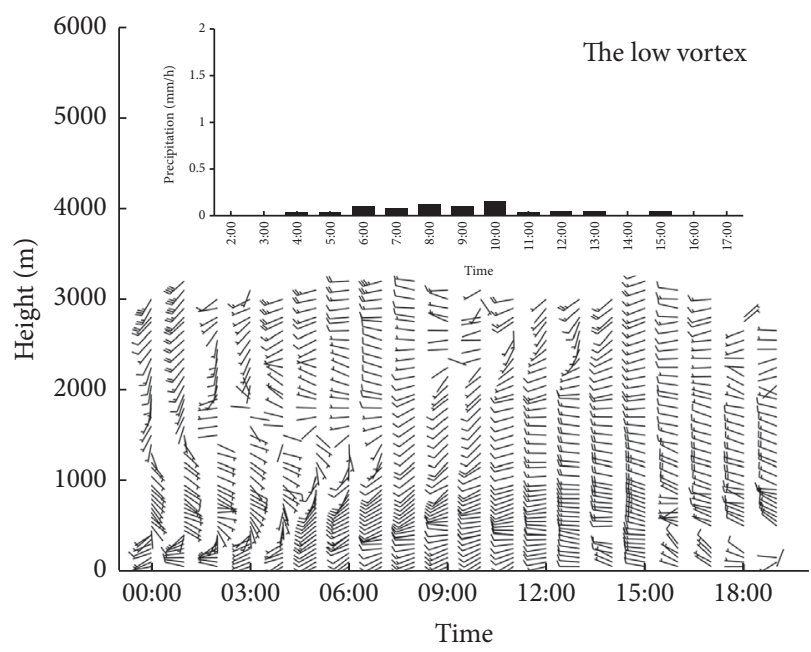

(a)

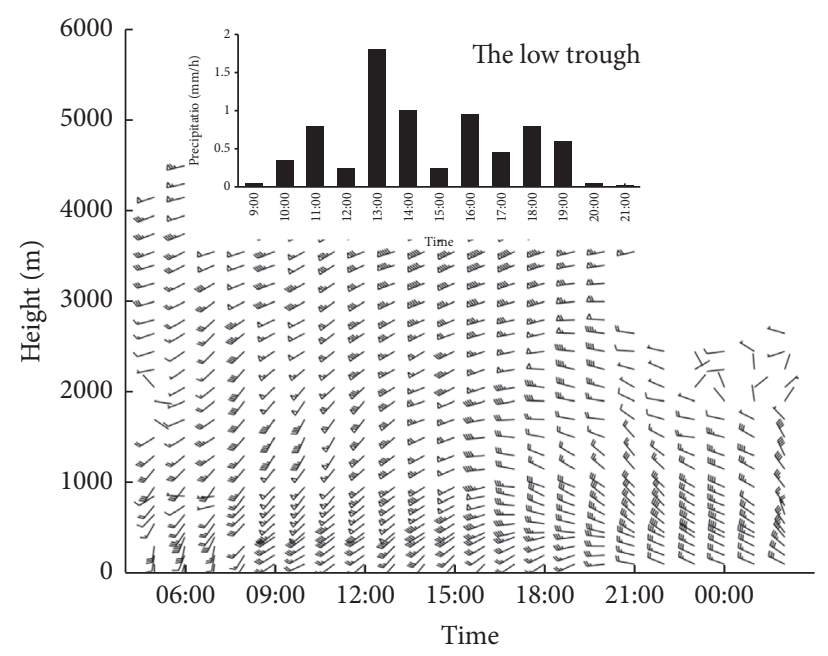

(b)

FIGURE 4: Evolution of wind and precipitation rate (black column) at Yan Jiaping under typical low vortex (case 9, (a)) and low trough (case 11, (b)) during snowfall. The height in $y$-axis is above the ground.

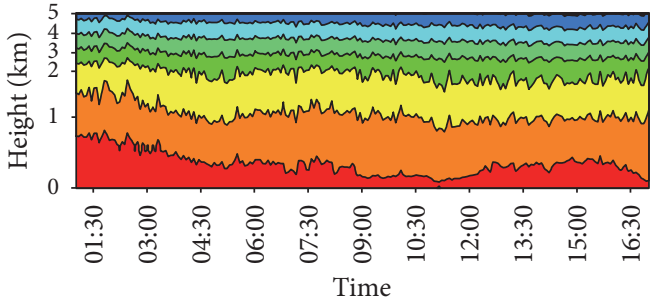

(a)

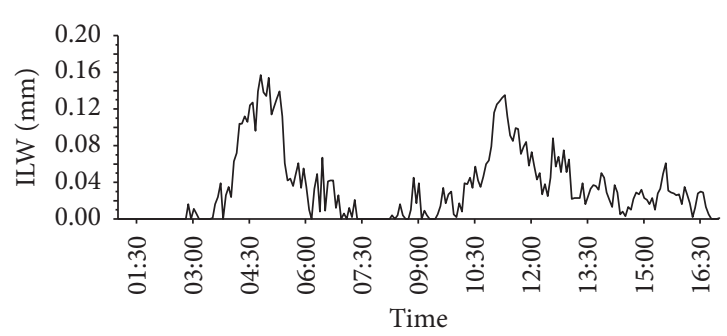

(c)
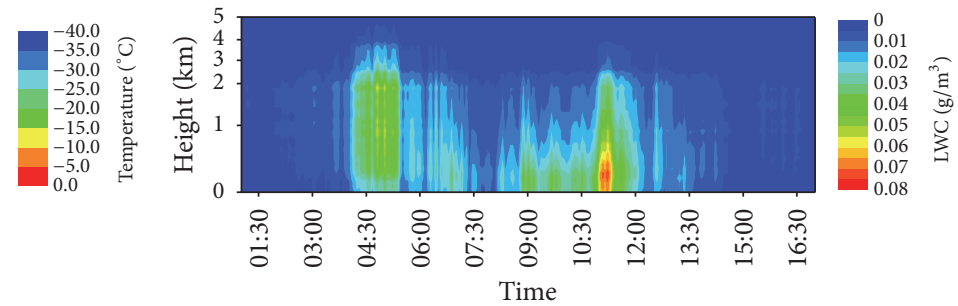

(b)

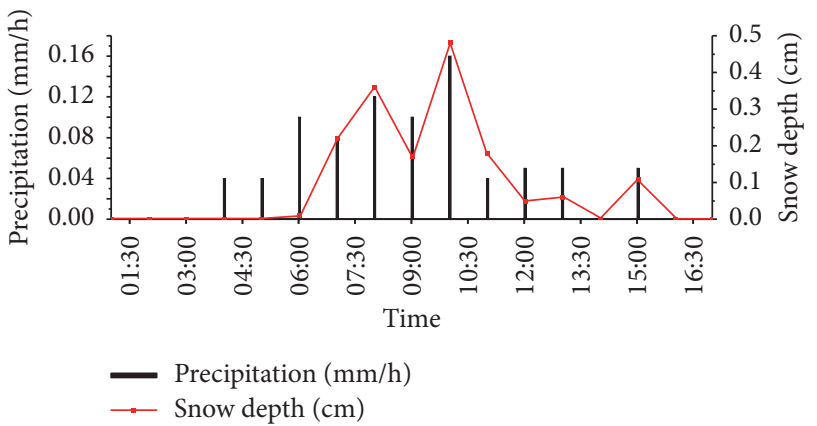

(d)

FIGURE 5: Evolution of temperature (a), LWC profile (b), integral liquid water (c), precipitation rate (black column), and snow depth (red line, (d)) at Yan Jiaping under typical low vortex (case 9) during snowfall. The height in $y$-axis is above the ground.

snowfall. Clouds therefore can be affected by aircraft-based snow enhancement, so the formation stage of any snowfall may be a favorable opportunity for aircraft-based cloud seeding.

The primary solid precipitation particles collected at YJP were planar dendrites, plates, bullets, and irregular particles without rimed and aggregates (Figures 7(d), 7(e), 7(f), and $7(\mathrm{~g})$ ). Graupel particles (Figure $7(\mathrm{~h})$ ) are however common in early winter (case 5) and, by the end of winter (case 12), the manned observation showed orographic cloud persisting for long periods at YJP during snowfall. Rime appears and ice accretion is evident on the ground observation instruments (not shown).

3.2.2. Steady Snowfall. During the stable period of snowfall, the wide-area cloud system was evident at the Haituo Mountains, becoming continuous and deep. Figure 6 shows that the cloud depth of the low trough (case 11, 0600-1300) is thicker than that of the low vortex (case 9, 1000-1900). The cloud top height in case 11 is near $7 \mathrm{~km}$ (mean echo intensity) with the corresponding temperature of below $-40^{\circ} \mathrm{C}$, while it is less than $4.5 \mathrm{~km}$ with corresponding temperature of only 


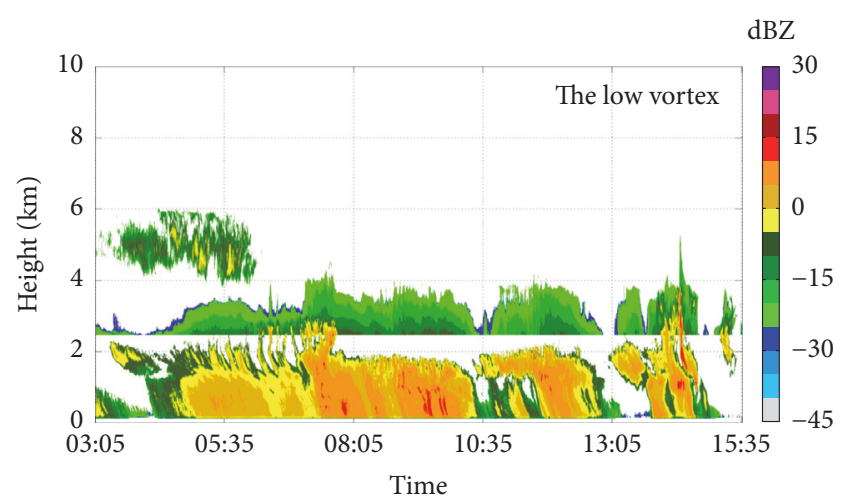

(a)

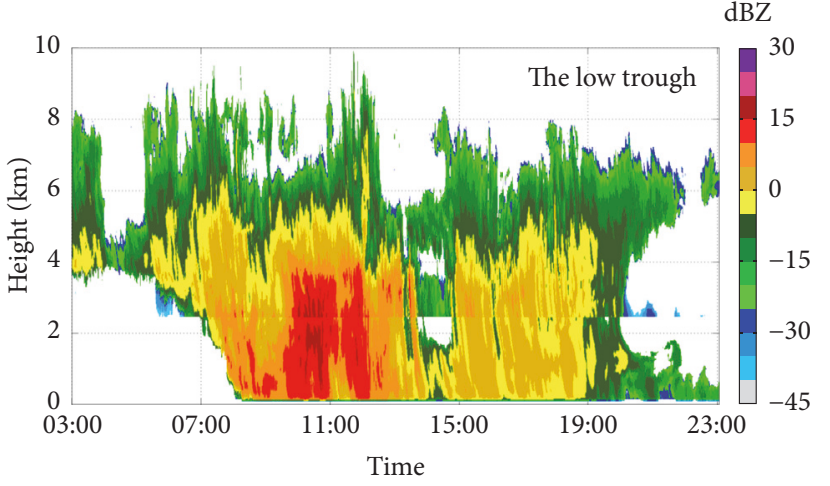

(b)

FIGURE 6: The echo evolution of cloud and precipitation at Yan Jiaping under typical low vortex (case 9, (a)) and low trough (case 11, (b)). The height in $y$-axis is above the ground.

about $-25^{\circ} \mathrm{C}$ in case 9 . Snowfall in the former increases to 10 times that of the latter. Cloud reflectivity in case 9 exhibited little variability with low-level reflectivity near $10 \mathrm{dBZ}$, but in case 11 cloud reflectivity reached $25 \mathrm{dBZ}$. This again indicates that the two typical synoptic conditions affect cloud structure which then affects the amount of snow on the ground.

Wind observation from the meteorological automatic station at Xi Dazhuangke and Chang Chonggou, which are in front of the Haituo Mountains, shows the southeasterly wind is dominant during snowfall (Figure 8, case 1 as an example). The wind profiler radar (Figure 4) shows the distribution of the maximum height of the southwesterly wind under the low vortex (case 9) to increase gradually from $2.3 \mathrm{~km}$ to $4.4 \mathrm{~km}$, at which time the orographic clouds climbed to the YJP (2 hours' duration). From the surface up to about $6.0 \mathrm{~km}$ however, the airflow over the Haituo Mountains under the low trough (case 11) is continuously controlled by the southwesterly wind, and the orographic clouds repeatedly move to the station. Moreover, the intensity and height of the southwesterly wind were higher than in case 9, and the corresponding snowfall was also significantly higher. This shows that the southwesterly wind plays an important role in the formation of snowfall and orographic clouds.

Snowfall and precipitation rate appear to be a function of southwest wind speeds. As the storm persists the ILW and LWC are gradually reduced (Figure 5). It should be noted that LWC at high altitude in the stable period of snowfall are little, but when the orographic clouds climbed to the YJP, the microwave radiometer observations showed that the ILW again appeared subpeak $(0.12 \mathrm{~mm} / \mathrm{hr})$, and the LWC profile in Figure 5 shows the distribution of LWC to be mainly below $2.3 \mathrm{~km}$. Therefore, the orographic clouds have the potential of ground-based (general height at $0.9-1.0 \mathrm{~km}$ ) snow augmentation. The occurrence of topographic clouds may be a favorable time to carry out cloud seeding by groundbased method.

Based on visibility meter data (not shown), visibility was generally below $100 \mathrm{~m}$ (partially below $50 \mathrm{~m}$ ) when the orographic clouds climbed to the YJP. The orographic cloud top was over $1344 \mathrm{~m}$, and the competition area of 2022 Winter Olympic Games in the Haituo Mountain is between $1.3 \mathrm{~km}$ and $2.2 \mathrm{~km}$. Orographic clouds limit the visibility on the racing track, and low visibility can be a serious safety concern to athletes and referees, and low visibility due to fog or snow may delay or postpone events associated with Winter Games [25]. Therefore, the orographic clouds during snowfall will impact the Winter Olympic Games and should be monitored.

Figure 7 shows examples of the solid precipitation particles collected at the YJP. Precipitation particles are generally rimed and aggregated dendrites, but rimed plate, plate, graupels and irregular particles also occur.

3.2.3. The End of Snowfall. As the southwesterly wind weakened, the snow of both the case 9 (1400-1600) and case 11 (2000-2100) reach the stage of dissipation, and the precipitation rate drops dramatically (Figure 4). The SLW is constantly consumed and weakened (Figure 5). Plates, columns, capped columns, irregular particles without being rimed and aggregates are common in the YJP (Figures 7(e), 7(f), and 7(i)), and it is likely that the crystals did not encounter the liquid water which indicates the lower SLW in cloud and no potential for cloud seeding during the end of the snowfall [26].

As the entire layer is controlled by the northwesterly wind, the snowfall stopped. The northwesterly wind is strong and blows the snow. In $100 \%$ of the 12 cases, strong wind occurs after snowfall. In 1988, high winds affected operations during the Calgary Winter Olympic Games [25]. The wind may also have huge impact on the 2022 Winter Olympics.

3.3. Microphysics of Snow Clouds. On 16 January 2016, a tilting trough system passed through the Haituo Mountain region. The high-altitude weather system in case 1 is similar to that of case 11, but the ground system differs. In case 1 and case 9, the ground synoptic situation is weak inverted trough, but low pressure controls the surface situation in case 11. The infrared satellite (not shown) indicates a cloud band extended from the northwest to southeast, covering the Haituo Mountains. Between 1800 and 0100, an upper-level cold front zone moved through the Haituo Mountains, and wind shear occurred at $850 \mathrm{hPa}$ during this time. Snowfall began at about 1900 and ended to 2400, and the maximum snow time was at 2000 (Figures 8(b) and 8(c)). 


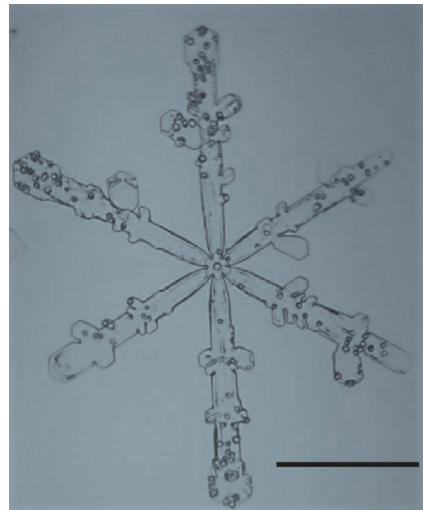

(a)

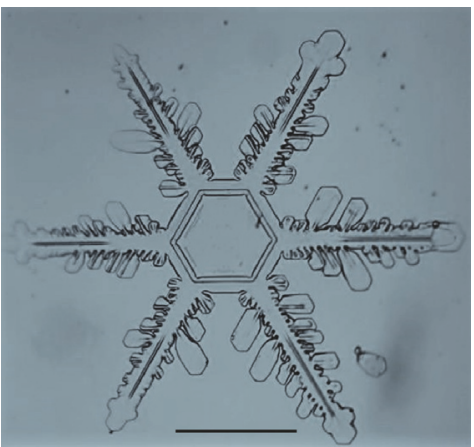

(d)

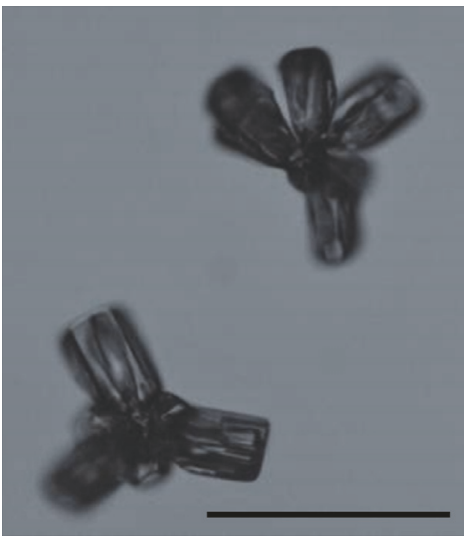

(g)

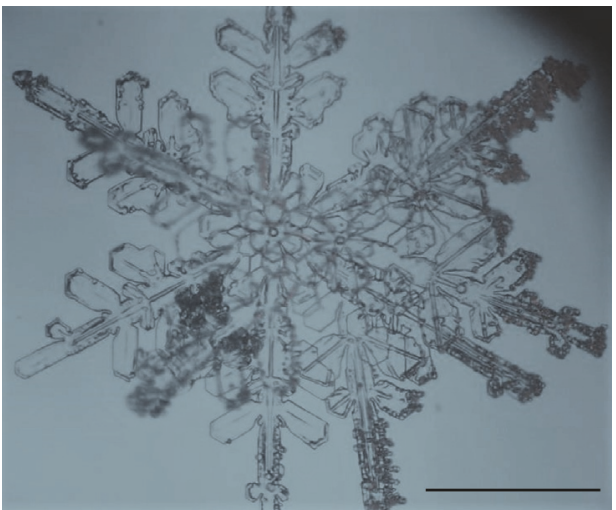

(b)

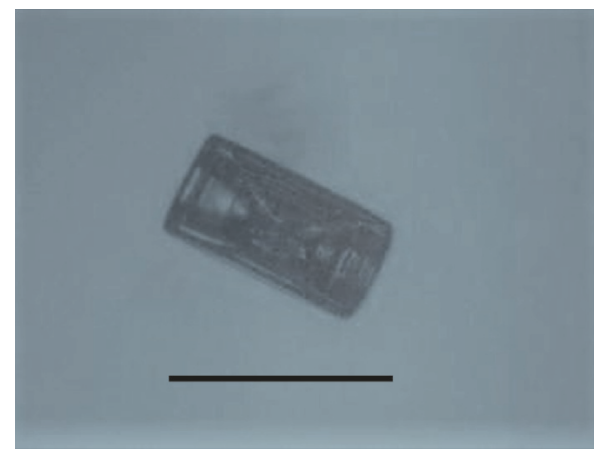

(e)

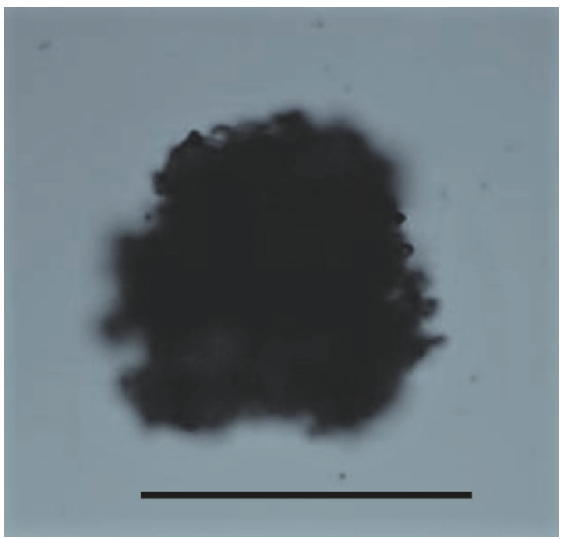

(h)

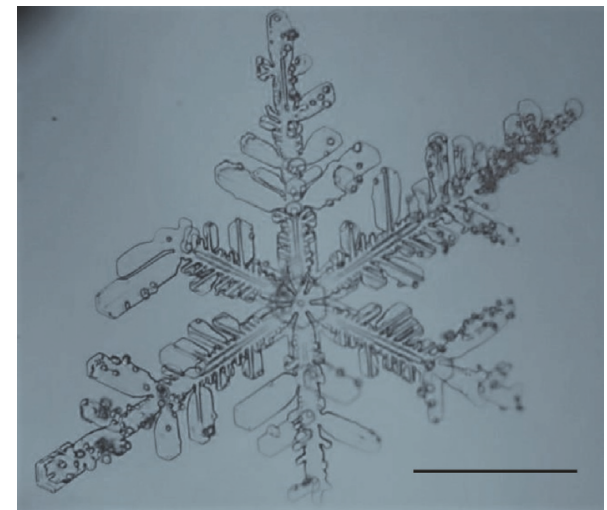

(c)

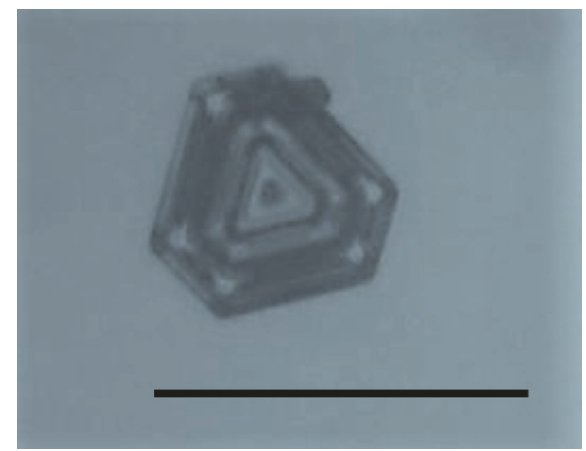

(f)

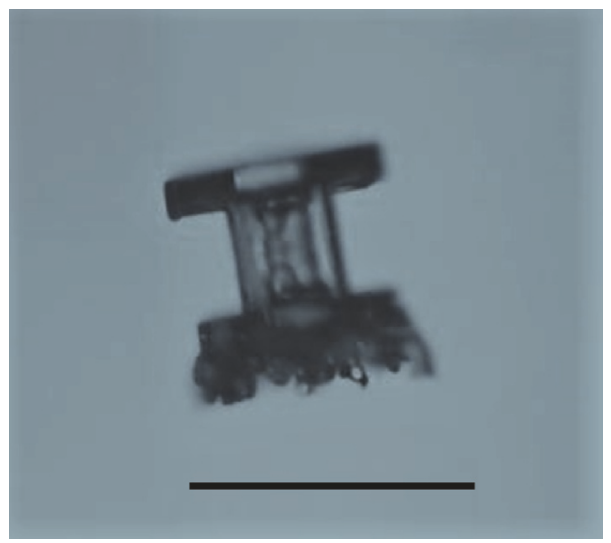

(i)

FIGURE 7: Some examples of solid precipitation particles collected at the Yan Jiaping in the Haituo Mountains. The black scale line represents $1 \mathrm{~mm}$.

The Kingair-350 aircraft measured the cloud microphysics characteristics above the Haituo Mountain area on 16 January 2016. The aircraft flies back and forth from northwest to southeast at 8 different altitudes, $6800 \mathrm{~m}, 5700 \mathrm{~m}, 5100 \mathrm{~m}$, $4500 \mathrm{~m}, 4000 \mathrm{~m}, 3500 \mathrm{~m}, 3200 \mathrm{~m}$, and $2900 \mathrm{~m}$, over the Haituo Mountain area (Figure 8(a)). The aircraft further penetrates the clouds from west to east over the Haituo Mountain. The cloud top is about $5800 \mathrm{~m}$. The flight time is from 1938 to 2037. We can see from Figures 8(a) and 8 (b) that the cloud penetration time corresponds with the biggest snowfall on the ground. Based on the limited flight measurement, the microphysical structure of snow clouds is analyzed and discussed as follows:

3.3.1. Ice Particle Shapes in Snow Clouds. The ice particle shapes are captured by 2DS probe. In the upper part of clouds (4000-5700 m), the ice particles are comparatively small. The main crystals are stellar crystal, column, irregular crystal, small graupel, and plate. In the middle layer of the clouds $(3500 \mathrm{~m})$, the ice crystal sizes are bigger than that of the upper clouds. The ice crystal shapes are similar to the upper part. In the lower part of clouds (3200 $\mathrm{m}$ and $2900 \mathrm{~m}$ ) the ice 


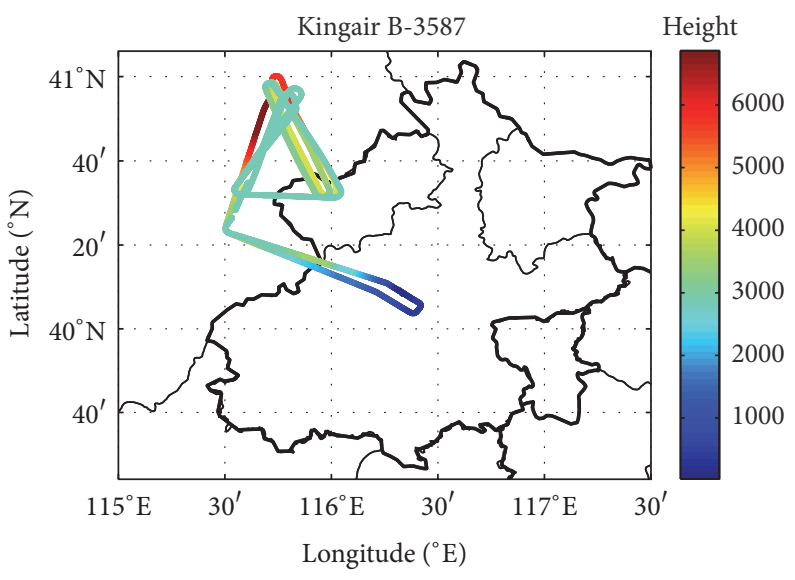

(a)

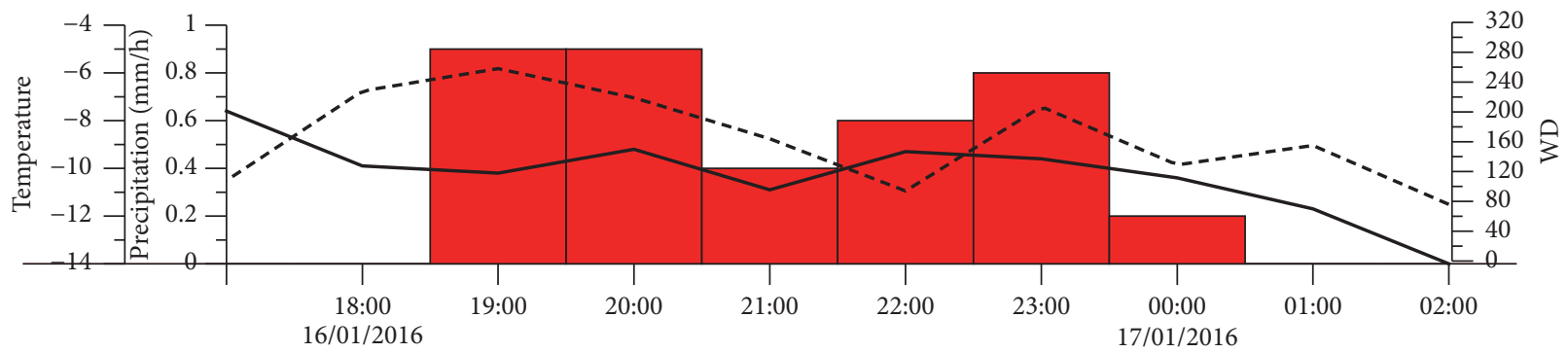

Chang Chonggou

Precipitation

- Temperature

- - - Wind direction

(b)

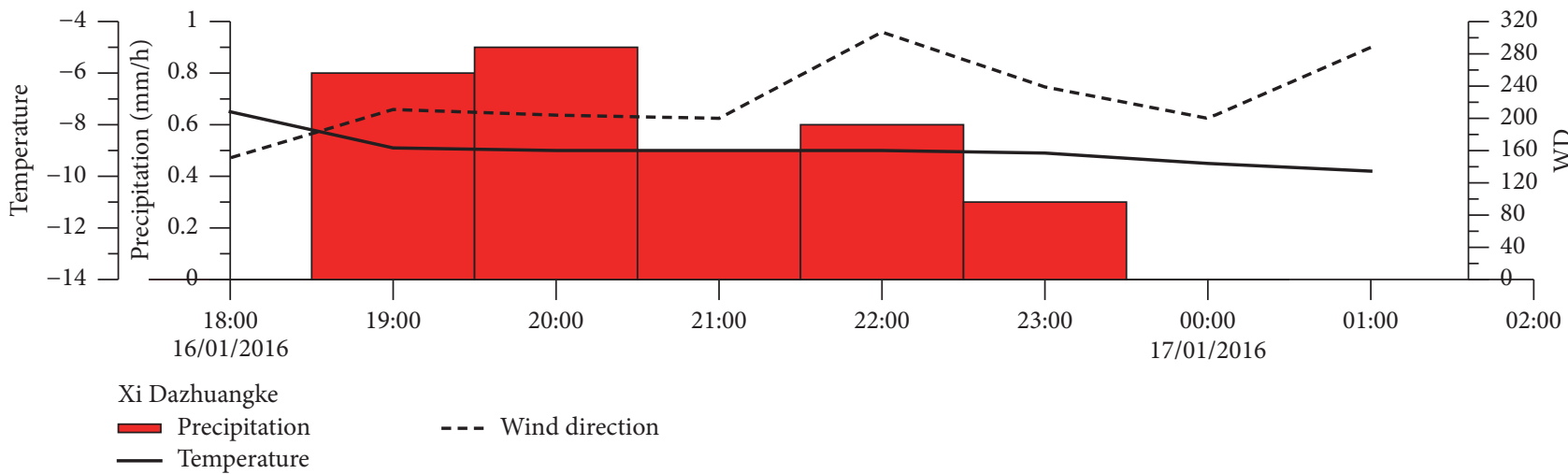

(c)

Figure 8: (a) The flight track in the Haituo Mountains under (red circle) upper trough weather condition (case 1); (b) Chang Chonggou weather elements time series; (c) Xi Dazhuangke weather elements time series.

crystal size is large. The crystal shapes are plate, stellar crystal, column, irregular crystal, and graupel. Frozen droplets are also found in the clouds, so are the rimed and clinging crystal. The crystal shapes in the lower clouds are the same as the ground observation.

3.3.2. Liquid Water Content and Ice Concentration. The liquid water content in clouds is calculated by FCDP probe in the aircraft. Ice concentration is measured by $2 \mathrm{DS}-\mathrm{H}$ channel (with $50 \mu \mathrm{m}$ resolution). Figure 9 shows the liquid water content and ice concentration at different heights, as well as the surface elevation below the aircraft. The cloud top height is about $5800 \mathrm{~m}$.

The liquid water content in the lower and middle layer of clouds is smaller than in the upper layer. The liquid water content in the clouds below $5100 \mathrm{~m}$ is less than $0.05 \mathrm{~g} / \mathrm{m}^{3}$. At $5700 \mathrm{~m}$, the liquid water content increases significantly and reaches as much as $0.2 \mathrm{~g} / \mathrm{m}^{3}$ with several peaks of $0.1-0.2 \mathrm{~g} / \mathrm{m}^{3}$. This shows that, in the stable stage of the snow cloud, the liquid water content is consumed. So, for case 1 , aircraft seeding still has the potential near the top of the cloud. 

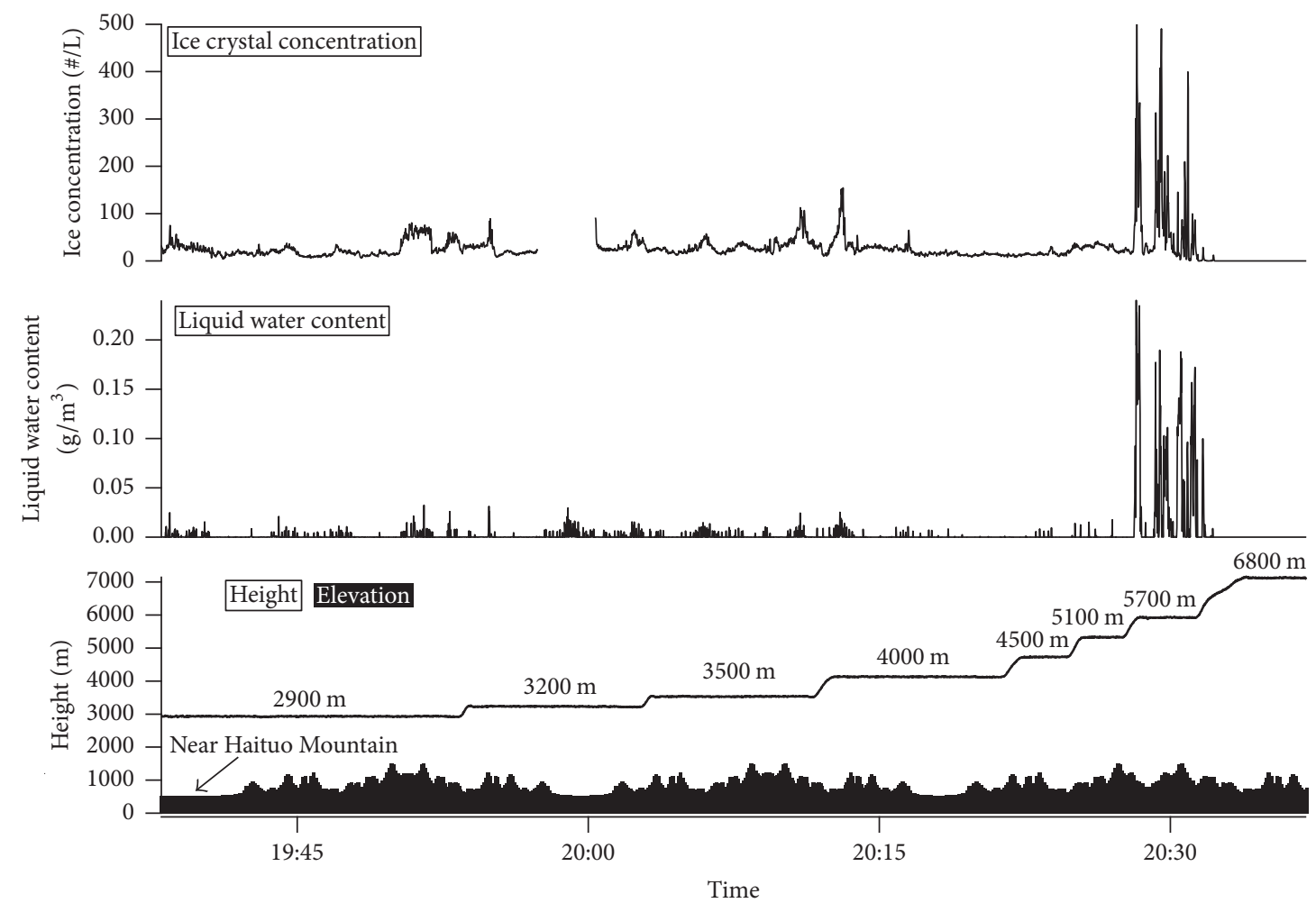

FIGURE 9: Liquid water content and ice concentration at different altitudes in case 1. (Black shade is the ground elevation under the flight track.)

More ice crystals exist near the top of the cloud than in the lower layer. The ice crystal concentration below $4000 \mathrm{~m}$ is $30 \sim$ $150 \# / \mathrm{L}$. It is less than $50 \# / \mathrm{L}$ at $4000 \mathrm{~m} 5100 \mathrm{~m}$. In the upper layer, however, the ice concentration could reach 450 \#/L. The region of the cloud near cloud top is found to be a primary source of ice particles in the clouds.

\section{Conclusions}

This paper describes the nature and properties of winter clouds and precipitation over the Haituo Mountains deduced from ground and airborne observations over the winter of 2016-2017. The principal characteristics are summarized below.

(1) The main synoptic systems are the trough and the low vortex at high altitude with convergence zone, inverted trough, or easterly returning current on the ground. The moderate or heavy snow often occurs when the low trough or vortex and the inverted trough or easterly returning current occur concurrently.

(2) Snowfall occurs only at night in $58 \%$ of the cases, and it snows only at daytime in $8 \%$ of cases. With an inverse trough surface synoptic ( 4 of the 12 case), it snows from night to daytime with the maximum duration of 20 hours. In $83 \%$ of cases, it snows for more than 3 hours. In $50 \%$ of cases, the precipitation lasts 5 to 10 hours. And more than 10 hours' snowfall duration time occurs in $33 \%$ of the storms. The maximum snowfall presented at the earlier stage (within 1 to 2 hours after the snowfall began) in $67 \%$ of the cases.
(3) $83 \%$ of orographic clouds in 12 cases result in visibility below $100 \mathrm{~m}$ and often climbs to YJP along the southeast and southwest of the valley during precipitation (except little snow) and return to the valley after the snowfall stopped. Some cases showed the orographic clouds repeated movement to the station, hovering in the valley at times.

(4) The duration and intensity of snow appear to be a strong function of southwesterly winds.

(5) SLW is greater at the start of the snowfall, and the clouds have the potential for aircraft-based snow enhancement, so the formation stage of snow may be a favorable opportunity for aircraft-based cloud seeding. When the orographic clouds reach the YJP, they have more SLW and have the potential of ground-based snow augmentation. The occurrence of orographic clouds may be a favorable time to carry out ground-based cloud seeding.

(6) During steady snowfall periods, the primary crystal habits collected at YJP are rimed and aggregated planar dendrites, similar to those observed by the aircraft in the lower cloud levels. The primary solid precipitation particles collected at YJP during both the early stage and at the end of the snowfall are planar dendrites, plate, and irregular particles without being rimed and aggregates.

\section{Conflicts of Interest}

The authors declare that there are no conflicts of interest. 


\section{Acknowledgments}

The authors wish to express gratitude to Professor Deping Ding and Mr. Mengyu Huang for valuable discussions concerning the observation of winter cloud and precipitation over the Haituo Mountains; Mr. Yang Gao, Mr. Wei Zhou, Mr. Ping Tian, Mr. Fei Wang, Mr. Jiujiang Sheng, and Mr. Xuebin Zhang, who participated in the aircraft observation; Mr. Fei Yang, Ms. Xincan Jia, Ms. Xing Zhang, Ms. Yan Yang, Ms. Xin Guo, and Mr. Bin Wu, who participated in the ground observation; and Mr. Hongyi Wu and Mr. Jianyong Liu, who analyzed the weather situation. This work was funded by the Natural Science Foundation of Beijing (Grant nos. 8172023 and 8164058), Science and Technology Project of Beijing Meteorological Service (Grant no. BMBKJ201506001), the National Natural Science Foundation of China (NSFC) under Grant no. 41775138, Beijing Municipal Science and Technology Commission (Grant no. D171100000717001), and the National Natural Science Foundation of China (NSFC) under Grant no. 41675138.

\section{References}

[1] Z. F. Zhang, S. Xi, N. Liu, Y. Yu, S. H. Fan, and M. N. Feng, "Snowfall change characteristics in China from 1961 to 2012," Resources Science, vol. 37, no. 9, pp. 1765-1773, 2015 (Chinese).

[2] B. Vonnegut, "The nucleation of ice formation by silver iodide," Journal of Applied Physics, vol. 18, no. 7, pp. 593-595, 1947.

[3] P. V. Hobbs, "The nature of winter clouds and precipitation in the Cascade Mountains and their modification by artificial seeding. Part I: nature conditions," Journal of Applied Meteorology, vol. 14, no. 5, pp. 783-803, 1975.

[4] P. V. Hobbs and L. F. Radke, "The Nature of Winter Clouds and Precipitation in the Cascade Mountains and their Modification by Artificial Seeding. Part II: Techniques for the Physical Evaluation of Seeding," Journal of Applied Meteorology and Climatology, vol. 14, no. 5, pp. 805-818, 1975.

[5] R. M. Rauber, "Characteristics of cloud ice and precipitation during wintertime storms over the mountains of northern Colorado," Journal of Applied Meteorology and Climatology, vol. 26, no. 4, pp. 488-524, 1987.

[6] Q. Wang, L. G. You, and Z. J. Hu, "The study on the winter stratocumulus cloud over Urumuqi, Xinjiang, China-structure and evolution," Acta Meteorologica Sinica, vol. 45, no. 1, pp. 2-12, 1987 (Chinese).

[7] L. G. You, S. R. Wang, D. F. Wang, and Y. M. Chi, "The microphysical structure of snow cloud and the growth process of snow in winter in Xinjiang," Acta Meteorologica Sinica, vol. 47, no. 1, pp. 73-81, 1989 (Chinese).

[8] G. H. Wang and L. G. You, "The microphysical structures and precipitation characteristics of the cloud zone over a wintertime cold front and stratocumulus under it in Urumuqi," Meteorology, vol. 5, no. 3, pp. 15-19, 1989 (Chinese).

[9] Y. B. Liu and L. G. You, "The mes- and small -scale structure and potential for cloud seeding of wintertime snowfall in the Zhungeer basin," Quarterly Journal of Applied Meteorology, vol. 1, no. 2, pp. 113-122, 1990 (Chinese).

[10] S. A. Tessendorf, B. Boe, B. Geerts, M. J. Manton, S. Parkinson, and R. Rasmussen, "The future of winter orographic cloud seeding a view from scientists and stakeholders," Bulletin of the
American Meteorological Society, vol. 96, no. 12, pp. 2195-2198, 2015.

[11] Z. G. Zang, W. Guo, X. T. Bai et al., "Winter ground wind field characteristic in the haituo mountain division for the 24th Winter Olympic Games," Journal of Arid Meteorology, vol. 35, no. 3, pp. 433-438, 2017 (Chinese).

[12] F. H. Ludlam, "Artificial Snowfall from Mountain Clouds," Tellus, vol. 7, no. 3, pp. 277-290, 1955.

[13] A. W. Huggins, "Summary of studies that document the effectiveness of cloud seeding for snowfall augmentation," Journal of Weather Modification, vol. 41, pp. 119-126, 2009.

[14] R. M. Rauber and L. O. Grant, "The Characteristics and Distribution of Cloud Water over the Mountains of Northern Colorado during Wintertime Storms. Part II: Spatial Distribution and Microphysical Characteristics," Journal of Applied Meteorology and Climatology, vol. 25, no. 4, pp. 489-504, 1986.

[15] M. F. Heggli and R. M. Rauber, "The Characteristics and Evolution of Supercooled Water in Wintertime Storms over the Sierra Nevada: A Summary of Microwave Radiometric Measurements Taken during the Sierra Cooperative Pilot Project," Journal of Applied Meteorology and Climatology, vol. 27, no. 9, pp. 9891015, 1988.

[16] A. W. Huggins, "Mobile microwave radiometer observations: spatial characteristics of supercooled cloud water and cloud seeding implications," Journal of Applied Meteorology and Climatology, vol. 34, no. 2, pp. 432-446, 1995.

[17] D. Q. Yang, Z. Z. Zhang, E. S. Kang, Y. S. Zhang, K. Elder, and R. Kattelmann, "Experimental study on comparability of snowfall measurement by precipitation gauge and snow survey," Advances in Water Science, vol. 3, no. 2, pp. 136-141, 1992 (Chinese).

[18] M. Löffler-Mang and J. Joss, "An optical disdrometer for measuring size and velocity of hydrometeors," Journal of Atmospheric and Oceanic Technology, vol. 17, no. 2, pp. 130-139, 2000.

[19] S. Lance, C. A. Brock, D. Rogers, and J. A. Gordon, "Water droplet calibration of the Cloud Droplet Probe (CDP) and inflight performance in liquid, ice and mixed-phase clouds during ARCPAC," Atmospheric Measurement Techniques, vol. 3, no. 6, pp. 1683-1706, 2010.

[20] R. P. Lawson, "Effects of ice particles shattering on the 2D-S probe," Atmospheric Measurement Techniques, vol. 4, no. 7, pp. 1361-1381, 2011.

[21] R. P. Lawson, B. A. Baker, C. G. Schmitt, and T. L. Jensen, "An overview of microphysical properties of Arctic clouds observed in May and July 1998 during FIRE ACE," Journal of Geophysical Research: Atmospheres, vol. 106, no. 14, pp. 14989-15014, 2001.

[22] L. Z. Zhong, L. P. Liu, R. S. Ge, and S. Feng, "A study of the calibration of the new generation of millimeter-wavelength cloud radar (HMBQ) and its detection capability," Acta Meteorologica Sinica, vol. 69, no. 2, pp. 352-362, 2011 (Chinese).

[23] C. Magono and C. W. Lee, "Meteorological classification of nature snow crystals," Journal of the Faculty of Science, Hokkaido University. Series 7, vol. 2, no. 4, pp. 321-362, 1996.

[24] Q. J. Yi, Y. Y. Liu, and C. H. Xu, "Synoptical and climatological analysis of snowfall from 1980 to 1994 in Beijing area," Journal of Applied Meteorological Science, vol. 10, no. 2, pp. 249-254, 1999 (Chinese).

[25] J. Horel, T. Potter, L. Dunn et al., "Weather support for the 2002 winter olympic and paralympic games," Bulletin of the American Meteorological Society, vol. 83, no. 2, pp. 227-240, 2002. 
[26] Y. G. Hong and F. F. Zhou, "The study of evaluation of potential of artificial precipitation enhancement in stratiform cloud system," Chinese Journal of Atmospheric Sciences, vol. 30, no. 5, pp. 913-926, 2006 (Chinese). 

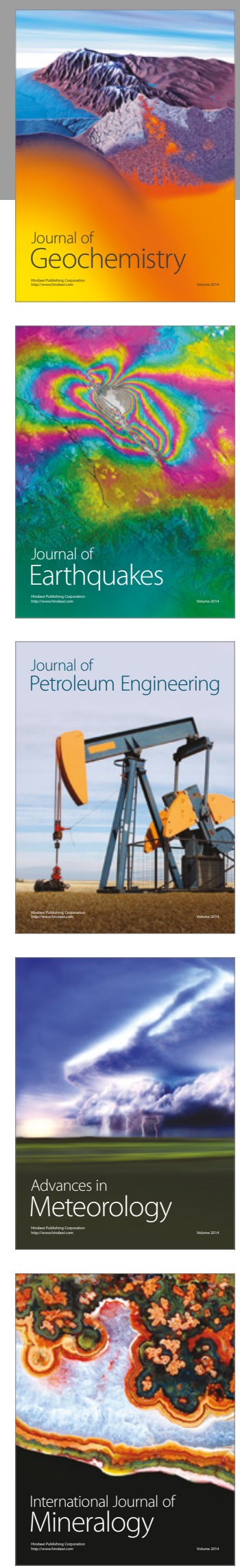
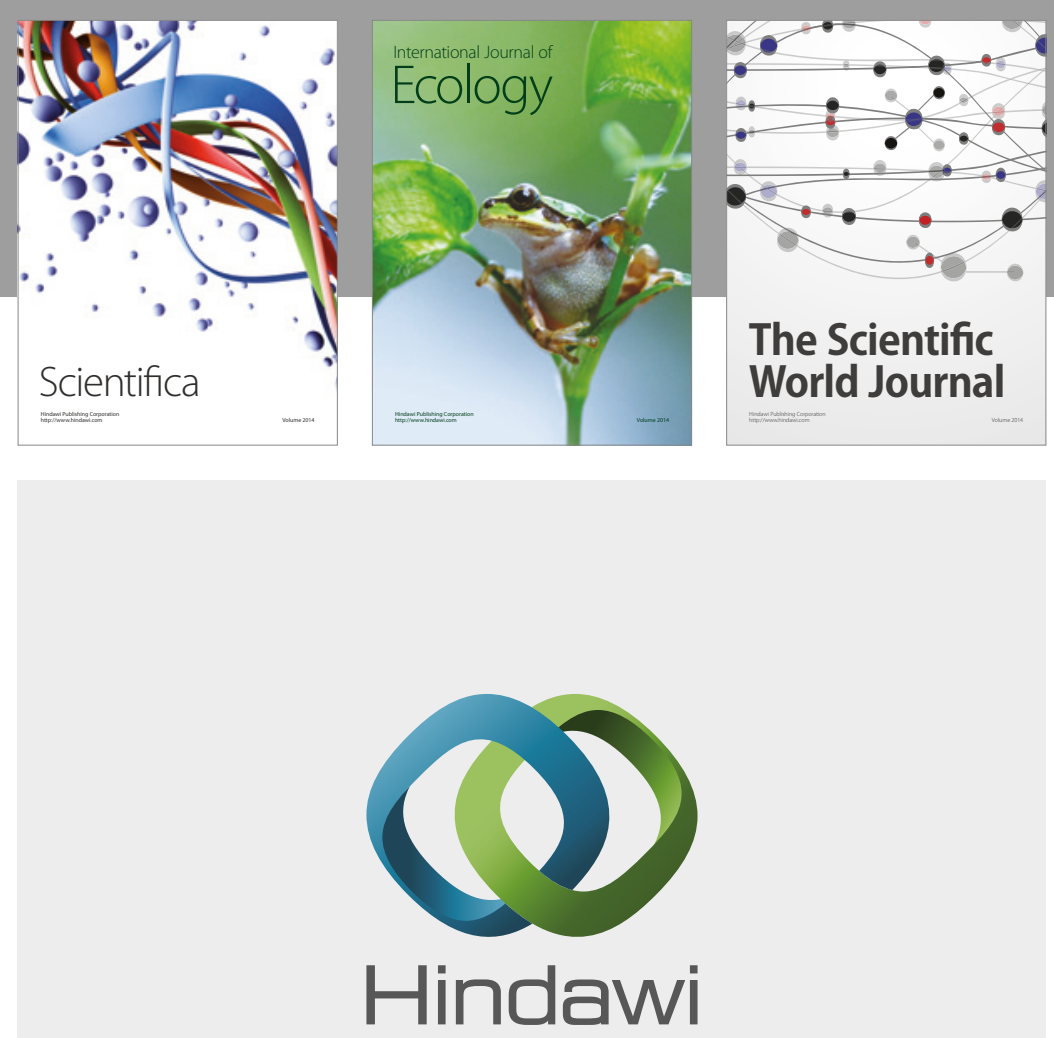

Submit your manuscripts at

https://www.hindawi.com
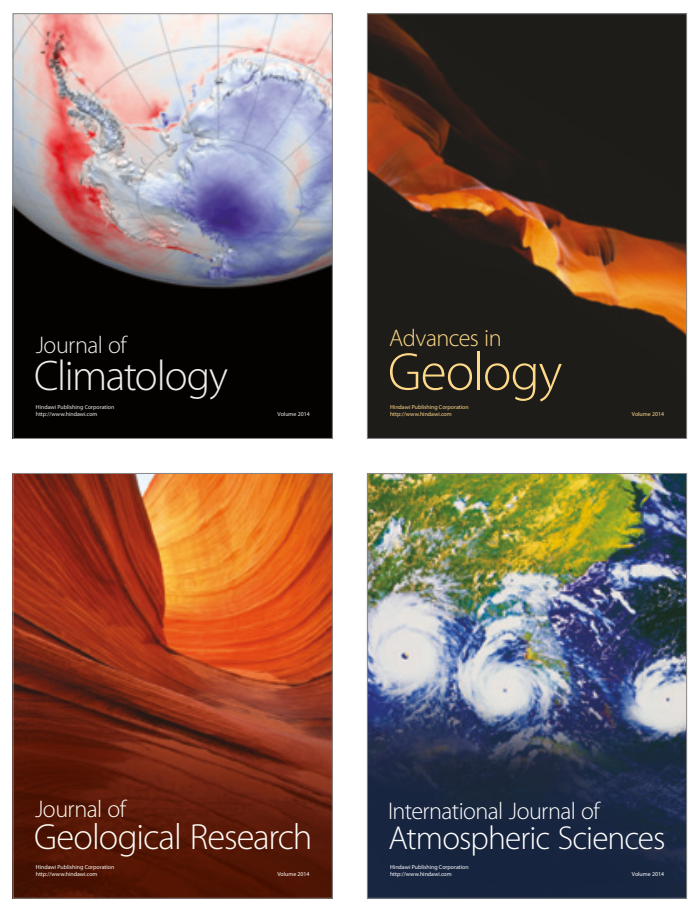

The Scientific

World Journal
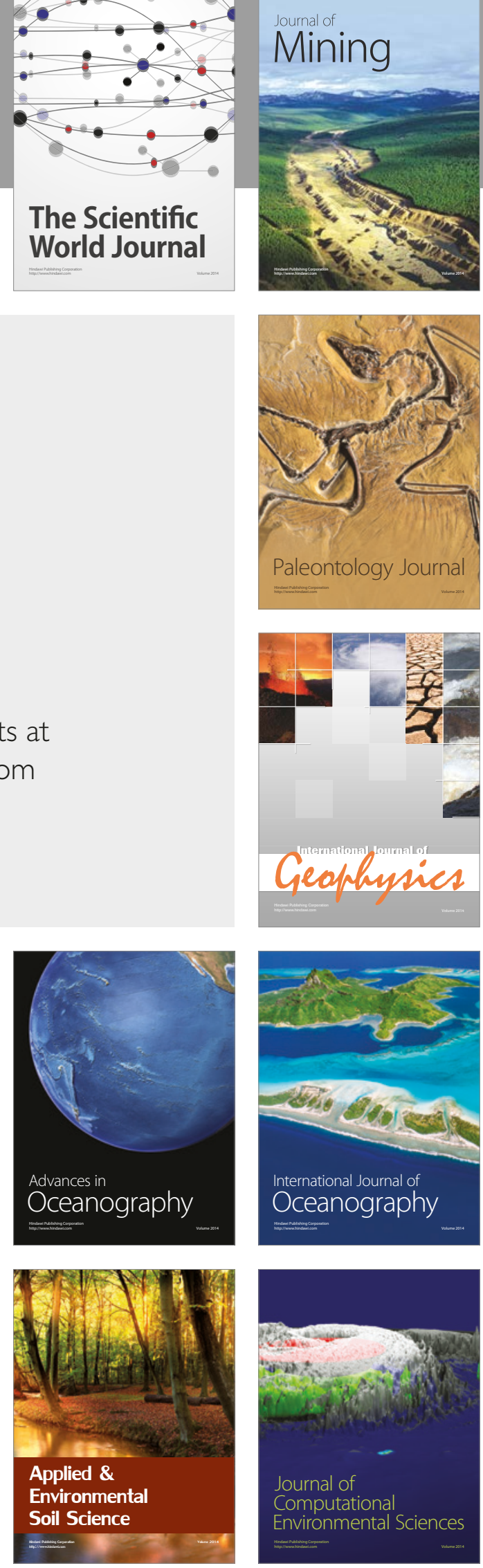